\title{
EXPERIENCIAS Y NARRACIONES EN TORNO AL USO DE TECNOLOGÍAS ANTICONCEPTIVAS (1970-2010): UNA PROPUESTA PARA SU ANÁLISIS Y DISCUSIÓN
}

\author{
Marcela Ramírez Hernández*
}

\begin{abstract}
Resumen: A partir de la década de 1960 empezaron a ingresar al país una amplia gama de nuevas tecnologías contraceptivas, la mayoría de ellas dirigidas a ser usadas por las mujeres. Cincuenta y cinco años después, ¿qué podemos descifrar al respecto desde sus vivencias? Este artículo examina a partir de las narraciones de un grupo de nueve mujeres josefinas, con edades entre los 25 y 71 años y de diferentes grupos ocupacionales, sus impresiones y experiencias en torno al empleo de métodos anticonceptivos. Su uso puede generar efectos colaterales en las usuarias, que además de hablarnos de procesos biológicos producto de la intervención de sustancias químicas en el cuerpo, nos susurra sobre aspectos relacionados con el poder, las resistencias, las negociaciones y las construcciones de género en las relaciones de pareja. Su estudio se aborda desde los aportes interpretativos que permiten los conceptos de habitus, performatividades de género y mecanismos disciplinarios, para reconocer la transformación o continuidad en las relaciones de poder que se gestan en torno a este aspecto en particular, vinculado con la vivencia de la sexualidad femenina y las decisiones sobre la maternidad.
\end{abstract}

Palabras clave: Anticoncepción, estudios de género, relaciones de poder, sexualidad, feminidad, Costa Rica.

Abstract: From the 1960's on, a wide range of new contraceptive technologies began to
enter the country, most of them targeted to be used by women. Fifty-five years later, what
can we establish about her experiences? This paper inquires, based on the narratives from
a group of nine San Jose women aged between 25 and 71 , and their impressions and expe-
riences on the use of contraception. Its use can cause side effects in users, plus biological
processes produced by the intervention of chemicals in the body. It makes statetemens
on power-related issues, resistance, negotiations and gender constructions in couple rela-
tionships. Their study is approached from the interpretative contributions allowed by the

Fecha de recepción: 04/09/2015 - Fecha de aceptación: 22/09/2015

* Costarricense. Egresada de la Maestría en Historia Aplicada de la Universidad Nacional. Correo electrónico:mhr85@hotmail.com 
concepts of habitus, gender performativity and disciplinary mechanisms, to recognize the transformation and/or continuity of power relationships that develop around this particular issue, also linked with the experience of female sexuality and childbearing decisions.

Keywords: contraception, gender studies, power relations, sexuality, femininity, Costa Rica.

\section{Introducción ${ }^{1}$}

$\mathrm{E}$ 1 uso de diversos métodos anticonceptivos, en combinación con múltiples variables sociales -como el ingreso de la mujer al mercado laboral, el acceso a la educación técnica y universitaria, la apropiación de algunos matices del discurso de liberación femenina y los feminismos, entre otros- han generado cambios en la forma en que muchas mujeres viven sus cuerpos y toman decisiones en relación con la maternidad: posponerla, buscarla o desplazarla del todo. Dentro de los roles asignados a hombres y mujeres en las sociedades patriarcales, la responsabilidad de la reproducción ha sido construida social y culturalmente como algo eminentemente femenino, responsabilidad que se extiende desde la prevención/cuidados del embarazo, hasta la crianza de sus hijos e hijas.

El mercado y la industria de la anticoncepción no rompen con este esquema, pues la mayor parte de las tecnologías contraceptivas creadas desde la segunda mitad del siglo XX se dirigen a ser usadas por las mujeres, a la vez que son ellas quienes visitan con más frecuencia los quirófanos por cirugías de esterilización, ante un índice apenas creciente, más no representativo, de hombres que optan por la vasectomía -cuadro 1-.

El presente artículo, más que estudiar la incidencia de la anticoncepción en los índices de fecundidad y natalidad -tema vastamente trabajado por especialistas de renombre ${ }^{2}$ - analizará las ideas, deseos y proyectos que engloban las decisiones en torno al uso que se hace de los métodos contraceptivos, tomando como referencia las vivencias narradas por un grupo de nueve mujeres, con edades que oscilan entre los 25 y 71 años, y que desarrollan sus actividades diarias, ya sea dentro de la academia, como profesionales no académicas o trabajadoras no especializadas o amas de casa. ${ }^{3}$

1 El contenido de este artículo corresponde a un extracto del III capítulo de la tesis en progreso, titulada provisionalmente "Transformación y continuidad en la construcción social del cuerpo femenino, en el mundo urbano josefino (1960-2010)", para optar al grado de Magister Scientae.

2 Algunos de los más mencionados y con bastantes estudios al respecto en los últimos cuarenta años son Luis Rosero Bixby, Arodys Robles y Manuel Gómez Barrantes, entre otros.

3 Para fines metodológicos, ese rango de edad fue dividido en tres subgrupos, con tres mujeres entrevistadas en cada uno: 1) de 25 a 40 años; 2) de 41 a 55 años y 3) de 56 en adelante. Así mismo, se procuró que, dentro de cada rango etario, una ejerciera como académica, otra tuviera estudios universitarios, pero no trabajara con la academia y, finalmente, una más que fuera trabajadora no especializada o ama de casa. Esto facilita reconocer procesos de continuidad y transformación/adaptación en sus discursos y prácticas, en función del contexto sociohistórico, su espacio social y nivel de estudios, y permite encontrar enlaces o divergencias en sus experiencias. 
En sus relatos asociados al uso de estas tecnologías, se encuentra la presencia de representaciones sociales asociadas a la feminidad, la liberación femenina y la maternidad responsable, entre otros elementos conformadores de sus subjetividades, e identificables por medio de la historia oral, la cual permite el reconocimiento de las diversidades en las experiencias de vida y la riqueza de perspectivas que estas encierran.

De esta manera, se procura analizar el rol que juegan los contraceptivos como mecanismos de disciplina corporal, que llegan a formar parte en la re-de-construcción de performatividades del género femenino y en la percepción y ejercicio de la autonomía sobre sí mismas. Pero la articulación de esa feminidad se estudia no solo a partir del uso de métodos, sino que se procura el reconocimiento de otras variables que median, evidenciado que dichas performatividades no tienen ejes permanentes o estables en el transcurso de vida de las mujeres, sino que se trasladan o varían en función del contexto, de sus experiencias, de cómo asumen sus cuerpos, así como de sus deseos y de la proyección de lo que quieren o han querido para ellas.

\section{Normas y (des)encuentros corporales: Experiencias en torno a la utilización de métodos anticonceptivos}

Dentro de la vida de las mujeres, el deseo de tener hijos e hijas o, por el contrario, de evitarles, ha sido el motivo que las lleva a buscar alternativas seguras, eficaces y cómodas para estos propósitos. Independientemente del grupo socioeconómico o perfil profesional de las entrevistadas, la preocupación por controlar la maternidad es una constante, sin embargo, hay ciertos principios de continuidad y significativas diferencias según su crianza, educación, edad y experiencia; además, existen distintos matices en la vivencia de este aspecto.

Entre los casos estudiados se identifican algunos elementos en común, conectados por los discursos de género -ya fuesen los más tradicionales o aquellos con clara influencia de los feminismos- que, evidentemente, traslapan las posibles diferencias existentes entre los habitus de clase o culturales; o al contrario, evidencian las divergencias de sus perspectivas de acuerdo con sus condiciones de vida y el acceso a la educación, espacios que permiten el reconocimiento de visiones alternas sobre la maternidad, la feminidad y las relaciones de pareja.

Para los propósitos de este estudio, el concepto de habitus será abordado desde la conceptualización aportada por el teórico francés Pierre Bourdieu. Este concepto puede ser comprendido como el proceso de interiorización de una serie de pautas sociales aprendidas a través de las relaciones de poder y los espacios con los que se vincula el sujeto. Dichas pautas pueden ser construidas desde las clases sociales y el género, entre otros, produciendo elementos de distinción entre las personas y contribuyendo a conformar el esquema de ideas que dan sentido a 
las acciones, pensamientos y percepciones, incluyendo la del cuerpo propio y el de las otras personas. Son aprehendidas de forma involuntaria por los individuos desde la infancia y son asumidas desde las colectividades, como verdades dadas: "hablar de habitus es plantear que lo individual, e incluso lo personal, lo subjetivo, es social, a saber, colectivo. El habitus es una subjetividad socializada". ${ }^{4}$

Además, como Bourdieu señala, el sujeto se presenta como un actor activo, pues a través del cuestionamiento, la crítica y la reflexión sobre estas "verdades", interviene en la producción de su habitus. En resumen, es:

"El elemento tanto generador de la práctica, como el factor primordial de la reproducción cultural y simbólica. Se define como el sistema de disposiciones durables y transferibles [...] que integran todas las experiencias pasadas y funciona en cada momento como matriz estructurante de las percepciones, las apreciaciones y las acciones de los agentes cara a cara a una coyuntura o acontecimiento y que él contribuye a producir". 5

El empleo de este concepto es central, en la medida que permite explicar factores clave que se identificaron, relacionados con la clase social y el nivel académico, pero también continuidades que trascienden los límites de la condición económica, como los roles de género.

Por otra parte, casi permanente es la presencia, en los relatos, de los principios de lo que Flórez-Estrada denomina el "discurso feminista liberal de profesionalización y apropiación del espacio público", ${ }^{6}$ una de las principales ideas articuladoras de sus pensamientos y actuaciones, en el cual los métodos contraceptivos han fungido como herramientas primordiales para controlar la reproducción y sus implicaciones, en pro de varios proyectos de vida. Sin embargo, se pudo identificar, también, que el momento de la vida en que algunas de las mujeres participantes conocieron y se apropiaron de este discurso, ha sido diferente.

\section{Sus experiencias}

Según los grupos de edad, fueron reconocidos algunos aspectos claves. Dentro del grupo de 56 años en adelante, la actitud de las mujeres hacia el uso de métodos de planificación parece haber sido bastante abierta, con significativas divergencias, según su proyección de vida y la manera en que visualizaban la

4 Pierre Bourdieu y Loï J.D. Wacquant, Respuestas por una antropología reflexiva (México, D.F.: Editorial Grijalbo, 1995), 85.

5 Pierre Bourdieu, La distinción. Criterios y bases sociales del gusto (Madrid, España: Editorial Taurus, 2000), 54, nota al pie de página. Itálica agregada.

6 María Flórez- Estrada Pimentel, De ama de casa a muliereconomicus (San José, Costa Rica: Editorial de la Universidad de Costa Rica - EUCR, 2011), 68-69. 
maternidad. "Rosa", 7 quien es académica universitaria, usó la píldora anticonceptiva como primera opción, con doble propósito según la prescripción médica: ganar peso y evitar los embarazos; sin embargo, abandonó esta alternativa por los efectos secundarios que le generaban. Inició a emplear el dispositivo intrauterino (DIU) - con el que quedó embarazada- pero que continuó usando. De la misma manera que varias de las entrevistadas -al menos 6 de las 9 mujeres-, la maternidad o el matrimonio no estuvieron dentro de sus prioridades durante su juventud, pues antes se preparó profesionalmente e inició carrera, de manera que la determinación de planificar estuvo en función de realizar varias de las metas que tenía propuestas, en donde la independencia económica y la estabilidad laboral tuvieron un eje central.

Por su parte, "Camila", la mayor de las mujeres en este grupo etáreo, es profesional pensionada y también realizó estudios superiores antes de casarse. En medio de un contexto en el que los efectos secundarios de la píldora estaban siendo fuertemente cuestionados, durante los primeros años de su vida marital, planificó con preservativo, ya que afirma que "para entonces la pastilla no se usaba tanto". "Su primer hijo llegó hasta después de diez años de matrimonio, y luego de pasar por tratamientos de fecundidad; tres años más tarde, el alumbramiento del segundo le significó serios problemas de salud que ponían en riesgo su vida, de manera que su esposo se realizó la vasectomía, para evitar los peligros del empleo de otro método de planificación. Sobre la cirugía ella comenta: "Estaba empezando la vasectomía, y nadie se la hacía, porque eso era como quedar, como dicen, quedar como un buey". 9

La historia de "Camila" es particular, en cuanto a que ella no tuvo que hacer uso de tecnologías contraceptivas que interfirieran directamente en su cuerpo, pues en un primer momento se valieron del preservativo y, posteriormente, fue su esposo quien se sometió a cirugía después del nacimiento de sus dos hijos, algo aún más particular si tomamos en cuenta que eso ocurrió a inicios de la década de 1980, cuando este procedimiento se empleaba apenas por el 0,5\% de la población, según encuestas de fecundidad -cuadro 1-. De acuerdo con sus

7 Todos los nombres usados que hagan referencia a mujeres entrevistadas, son ficticios. Se asignan para brindar coherencia y distinguir el perfil de cada una.

8 Se debe tomar en cuenta que la afirmación de la entrevistada puede estar influenciada por un contexto en el que el uso de la píldora era fuertemente cuestionado desde diferentes flancos. Cuando ella contrajo nupcias a inicios de la década de 1970, la prensa publicaba con frecuencia artículos que advertían sobre los efectos adversos de este en la salud de la mujer. Por ejemplo, La Nación, "Señalan más daños a causa de la píldora", 6 de mayo de 1978, 24. Así mismo, al finalizar la década de 1960, las jerarquías de la iglesia católica se opusieron al empleo de la píldora, pues consideraban incentivaba el egoísmo anti reproductivo en el núcleo familiar, a la vez que concedía a la mujer libertades sobre su cuerpo y la reproducción que esta institución nunca ha contemplado. Una compilación significativa sobre artículos periodísticos referentes al tema puede ser consultada en la bibliografía de: Mayra Cartín Brenes y María Rojas Muñoz, "Métodos anticonceptivos en el siglo XX: Mujeres que se opusieron a maridos, familia y credo religioso", Revista Costarricense de Salud Pública (Costa Rica) 22 (2013): 169-178.

9 Entrevista personal a Camila, San José, Costa Rica, 3 de octubre de 2014. 
declaraciones, esta cirugía en hombres tenía connotaciones sociales peyorativas, que ponían en duda la virilidad -“quedar como un buey”-, pero la decisión fue tomada en conjunto, pues mediaba el riesgo de muerte para "Camila", si ella era esterilizada en un momento de debilidad física.

\section{Cuadro 1}

\section{Uso de métodos anticonceptivos no tradicionales en mujeres casadas y en unión libre. Porcentajes (1976-2010)}

\begin{tabular}{|l|cccccccc|}
\hline \multicolumn{1}{|c|}{ Método/ Año } & $\mathbf{1 9 7 6}$ & $\mathbf{1 9 7 8}$ & $\mathbf{1 9 8 1}$ & $\mathbf{1 9 8 6}$ & $\mathbf{1 9 9 3}$ & $\mathbf{1 9 9 9}$ & $\mathbf{2 0 0 9}$ & $\mathbf{2 0 1 0}$ \\
\hline Píldora & 23 & 23,3 & 20,6 & 19,2 & 18 & 25,6 & 24,7 & 21,3 \\
Salpingectomía & 14,7 & 14 & 17,3 & 16,7 & 19,7 & 21,4 & 28,3 & 30 \\
Condón & 8,6 & 8,7 & 8,4 & 12,9 & 15,7 & 10,9 & 7,7 & 9 \\
DIU & 5 & 4,8 & 5,7 & 7,4 & 8,7 & 6,9 & 2,8 & 3,4 \\
Inyección & 1,9 & 2 & 2,2 & 1,2 & 1 & 5,9 & 8,1 & 9,5 \\
Vasectomía & 1 & 0,8 & 0,5 & 0,5 & 1,3 & 0,5 & 4,7 & 5,9 \\
\hline
\end{tabular}

Fuente: Elaboración propia basada en Encuestas de Fecundidad y Salud Reproductiva. Asociación Demográfica Costarricense, 1976, 1981, 1986. Caja Costarricense del Seguro Social. 1993, 1999, 2009, 2010.

Distinto a las dos mujeres anteriores, es el caso de "Jimena", quien es ama de casa y trabajó en fábricas josefinas desde la adolescencia, durante la época de auge industrial en San José a inicios de los sesenta. El deseo de la maternidad fue una constante, de forma que contrajo matrimonio al ser mayor de edad, con la esperanza de ser madre pronto; sin embargo, disposiciones biológicas le significaron un freno: usó píldoras bajo prescripción médica para controlar procesos hormonales, pues tenía irregularidades que le impedían llevar a término los embarazos. Así, logró tener 4 hijos con diferentes intervalos de espaciamiento, que dependían de los ciclos naturales, pues no utilizaba contraceptivos.

Como se evidencia en los casos de estas tres mujeres, el uso de métodos de planificación no era la principal de sus preocupaciones, sino que más bien fungió como un medio para otros propósitos: para evitar un embarazo o para procurarlo controlando los ciclos hormonales, ${ }^{10} \mathrm{o}$ también en busca de los efectos colaterales, como lo es cambiar la contextura del cuerpo. Recurrir a estas tecnologías tuvo en cada caso fines diferenciados, que además se conectan con el habitus de cada una, en donde la condición socioeconómica, y sus historias y perspectivas de vida podrían ser factores que marcaron una diferencia en cuanto a la circulación de

10 Guillermo Galán, "50 años de la píldora anticonceptiva”, Revista Chilena de Obstetricia y Ginecología (Chile) 74, n. 4 (2010).

Disponible en http://www.scielo.cl/scielo.php?script=sci_arttext\&pid=S0717-75262010000400001 
ideas y opciones de roles de género a asumir, por ejemplo, el momento en que se deseaba la maternidad y el sitio que esta ocupó dentro de sus prioridades.

Asimismo, se identifica que no hubo un cambio constante entre tecnologías contraceptivas, sino que a lo sumo hicieron uso de dos de ellas, más que por un asunto de contexto o reacciones a los medicamentos, por las experiencias de vida particulares que se mostraron anteriormente.

Situación contraria se encontró en el grupo de mujeres de 41 a 55 años. En el caso particular de dos de ellas, declararon haber hecho uso de casi todos los métodos anticonceptivos disponibles; sin embargo, las reacciones físicas ante agentes externos a su organismo en unos casos, o la mala praxis médica en otros, jugaron en su contra.

"Daniela", ${ }_{11}$ quien es estilista, ama de casa y madre de tres hijos, inició su recorrido por la maternidad a la temprana edad de 16 años, por un embarazo no deseado mientras intentaba planificar con el ritmo: no sabía usar otro método y, por ende, es probable que tampoco supiera o pudiera sacar las cuentas de la manera "adecuada". Esto ocurrió a inicios de la década de 1980, años caracterizados por las fuertes discusiones que se dieron por el aumento en los índices de madres adolescentes, y en donde los jerarcas eclesiásticos y los sectores conservadores culpaban al machismo y a la liberación femenina ${ }^{12}$ de este y otros fenómenos sociales, muchos de ellos agudizados por la crisis económica por la que atravesaba el país.

Daniela afirma que las causas de su primer embarazo fueron la falta de educación sexual -tanto en la familia como en el colegio- y la consiguiente ignorancia sobre los procesos reproductivos, lo que nos habla sobre la persistencia de estructuras conservadoras e ideologías religiosas dentro de las familias y el sistema educativo, en donde el tema de la sexualidad de las mujeres no se abordaba del todo o se desarrollaba dentro de un esquema anatomista, obviando la enseñanza sobre el uso eficiente y responsable de los métodos contraceptivos.

La experiencia de ser madre adolescente la motivó a la planificación. En un primer momento fue medicada con píldoras que le produjeron una subida repentina de peso y retención de líquidos; pasó entonces a la inyección, que alteró su presión arterial y le generaba migrañas; haciendo uso del preservativo y el ritmo, quedó embarazada de su segundo hijo; los dispositivos intrauterinos le ocasionaron dismenorreas, inflamación y un aborto, y después tuvo su tercer embarazo. A partir de la consulta con una ginecóloga, fue víctima de mala praxis por el cambio de un dispositivo, que la llevó a la salpingectomía y, ante problemas con uno de sus ovarios, le realizaron una cirugía de histerectomía. Lejos de

11 Entrevista personal a "Daniela", San José, Costa Rica, 16 de abril de 2014.

12 Fabio Muñoz, "La madre soltera: Machismo y liberación fémina, las causas", Contrapunto, 16 de julio de 1981, 8; La Prensa Libre, "Fracasa educación sexual”, 30 de septiembre de 1983, 1, Segunda Sección; La Prensa Libre, "Falta educación hacia el amor", 4 de octubre de 1983, 15. 
sentir pesar, pues desde la menarquía tuvo molestias durante la menstruación, "Daniela" afirma: "Para mí, lo mejor de lo mejor, de lo mejor, de lo mejor, fue que me cortaran los tubos. Y todavía -como dicen los polos- más mejor, fue cuando me sacaron el útero, porque ya no tengo menstruación, entonces eso fue para mí, la maravilla". ${ }^{13}$

La búsqueda de la manipulación de los procesos biológicos para evitar el embarazo, se tornó para "Daniela" en un continuo de pruebas con varias tecnologías anticonceptivas, todas con significativos efectos secundarios sobre su cuerpo, que hacían de los ciclos y periodos menstruales momentos de enemistad consigo misma. Ella no lo podía controlar; de alguna manera, tenía que ceder ese control a la ciencia y al médico.

Desde la perspectiva de la medicina, la fecundidad ocurre como consecuencia de procesos hormonales, que la ciencia ha identificado y validado, y con ello, construye la realidad de los cuerpos, a la vez que los inscribe dentro de los parámetros anatómicos y socioculturales que construyen el género. ${ }^{14}$ La materialización de dichos procesos, en cierta medida, se reconoce a través de la creación de medicamentos capaces de controlarlos, este es el caso de los contraceptivos. Sin embargo, la práctica médica y la fabricación de medicamentos permanece permeada por la visión del cuerpo femenino como una máquina, en donde se asume que su anatomía es manipulable, ensamblable en pro de objetivos definidos, ${ }^{15}$ sin tomar en mayor consideración los efectos secundarios de introducir sustancias sintéticas o extraer ciertos órganos. En particular, el cuerpo de las mujeres ha permanecido altamente expuesto a este tipo de prácticas, en tanto la prevención de la reproducción se ha convertido en una performatividad del género femenino, cuya responsabilidad está inscrita no solo en la biología, sino en una actitud socialmente deseable, necesaria en lo que actualmente constituye el ser mujer.

Un ejemplo de ello es la prescripción de varios métodos y la práctica despreocupada que se puede dar ocasionalmente en consulta, con las consecuencias directas que desembocaron en intervenciones quirúrgicas. Para "Daniela", la histerectomía es la mejor decisión que ha tomado en lo que respecta a su cuerpo, pues así evita las molestias del periodo menstrual, fue "un alivio total", a pesar de que reconoce que el trato en la consulta ginecológica difícilmente brinda la oportunidad de comunicar de manera eficiente sus síntomas reales. ${ }^{16}$

13 Entrevista a Daniela.

14 Thomas Laqueur, La construcción del sexo: Cuerpo y género desde los griegos hasta Freud (Barcelona, España: Ediciones Cátedra, 1994), 265-266.

15 Oliva López Sánchez, Enfermas, mentirosas y temperamentales: La concepción médica del cuerpo femenino durante la segunda mitad del siglo XIX en México (México, D.F.: Plaza y Valdés, 1998), 74.

16 En relación con el trato a las mujeres en la atención en obstetricia: Gabriela Arguedas Ramírez, "La violencia obstétrica: Propuesta conceptual a partir de la experiencia costarricense", Cuadernos de Inter.c.a.mbio sobre Centroamérica y el Caribe (Costa Rica) 11, n.1 (enero- junio, 2014): 145-169. 
La experiencia anterior se repite en "Rebeca", una profesional académica del mismo grupo etáreo, que inició el consumo de píldoras desde la adolescencia, y quien mantiene una opinión de aprobación y aversión hacia los métodos de planificación, pues pasó por un proceso semejante al de "Daniela", exceptuando las cirugías:

"El problema es que los anticonceptivos son pero una literal porquería. Los anticonceptivos están hechos por los hombres para controlar a la mujer, porque la mayoría de los anticonceptivos se los dan a la mujer, ni siquiera hay investigaciones serias sobre las consecuencias que pueden llegar a tener a largo plazo. Fíjate que yo planifiqué con muchos de ellos. Sin mentira, el uso de las pastillas para mí significaba: ¡Qué mierda! Me tengo que tomar esto y nos hace mierda el cuerpo, pero ¿por qué simplemente no hay otras cosas que sean más fáciles de usar y que no me causen daño?". ${ }^{17}$

En siete de las nueve mujeres consultadas, el común denominador fue la existencia de reacciones físicas o emocionales ante el uso de las píldoras anticonceptivas: manchas en la piel, depresión, irritabilidad, dismenorrea, cambios en el peso, etc., si bien no se pueden negar las benevolencias de este método, en tanto facilita la autodeterminación sobre la sexualidad y la reproducción, también es necesario recalcar el papel que juegan como mecanismos disciplinarios y guiones performativos, ${ }^{18}$ principios que de alguna manera, permiten reconocer el descontento de "Rebeca".

Según Michel Foucault, los discursos del poder presentan algunas claves o tácticas que mueven a los individuos a la acción, sin que sus principios operativos sean percibidos como órdenes, sino incluso, como un buen consejo o en la noción de tener libertad de decisión ${ }^{19}$ ante una amplia gama de opciones. En mayor o menor medida, según estemos permeados por el discurso del poder, se ejecutan las prácticas que este nos enuncia y llegan a ser asumidas como algo natural o que no se cuestiona. Así, el uso de la píldora y de las otras tecnologías contraceptivas creadas desde la segunda mitad del siglo XX, dirigidas a las mujeres, se inscriben dentro de este patrón, pues efectivamente su uso requiere de una serie de mecanismos disciplinarios que garantizan el control sobre las capacidades reproductivas de los cuerpos femeninos -en muchísima mayor medida que el cuerpo de los hombres-, significan una serie de rituales que van desde la visita

17 Entrevista personal a Rebeca, San José, Costa Rica 17 de noviembre de 2014.

18 Esta variable en su anglicismo, script, es empleado por Tania Cuevas Barberousse, "Tecnologías contraceptivas y feminidad: La pastilla como un script de género", Revista Reflexiones (Costa Rica) 93 (2014): 115-127.

19 Michel Foucault, Seguridad, territorio y población (México, D.F.: Fondo de Cultura Económica - FCE, 2006), 18. 
médica, su aprobación y consejo para la prescripción, hasta las rutinas diarias que algunos métodos demandan para garantizar su eficacia.

Son performativos en tanto remarcan la maternidad como una característica inherente al género y cuerpo femenino, ${ }^{20}$ pero principalmente, convierten la posibilidad del embarazo en un peligro que hay que sortear. Es decir, la repetición de la acción de prevenir se ha llegado a asumir como una tarea casi exclusiva de la mujer, y no se rompe ni se discute el ciclo ideológico mujer $=$ gestación $=$ responsabilidad, sino que, de cierta manera, se legitima con la idea de la contracepción; sin dejar de lado que las alternativas de uso que ha creado la industria se han fijado en los ciclos reproductivos de las mujeres. Por tanto, sin negar el margen de autodeterminación que permiten, y la incidencia que han tenido en otras áreas de la vida, tal vez es necesario reconocer la otra cara de la moneda, la que cuestiona su carácter intrínsecamente emancipador. ${ }^{21}$

Pero también existen resistencias dentro de las entrevistadas. Este es el caso de "Adriana", una joven empresaria del grupo de 25 a 40 años, casada y sin hijos, quien renunció al uso de métodos anticonceptivos que intervinieran directamente en su cuerpo, y expone, además, en su relación de pareja, una construcción diferente de las cargas para evitar la reproducción por mutuo acuerdo. La repartición de la responsabilidad ante este tópico se enmarca en la importancia del apoyo y el diálogo dentro de la relación. Pero a la vez, algunos matices del vocabulario empleado por la entrevistada denotan el poderío que, ella reconoce, socialmente poseen los hombres en la decisión sobre la preñez y sobre el cuerpo mismo de las mujeres, en especial con el método empleado por ellos como matrimonio, pues al ceder totalmente el control sobre la anticoncepción a su esposo se reconoce comprometida, pero principalmente, despreocupada y en confianza:
"No me gusta meterme cosas al cuerpo. Ahorita, así es como planifico, con el ritmo, y no he quedado embarazada en ocho años, y yo no soy la que lo llevo, es mi esposo. Le voy a decir algo: si me esposo quisiera dejarme embarazada, ya podría haberme dejado. Yo nunca me acuerdo cuándo me viene la regla, no lo sé. Yo le cedí el control, y he cedido muchas cosas así". 22

20 Según Judith Butler, a grandes rasgos "la performatividad no es un acto único, sino una repetición y un ritual que consigue su efecto a través de su naturalización en el contexto de un cuerpo, entendido, hasta cierto punto, como una duración temporal sostenida culturalmente". Así, lo que se interioriza como una serie de cualidades naturales al sexo, son construcciones sociales que estilizan los cuerpos, y que pasan por el comportamiento, los gestos, la presentación externa y los roles sociales. Judith Butler, El género en disputa y la subversión de la identidad (Barcelona, España: Ediciones Paidós, 2007), 17, 84.

21 Cuevas. Los trabajos de la autora mencionada se han centrado en examinar la continuidad de los roles de género más tradicionales, específicamente en el uso de la píldora. También se puede consultar: Tania Cuevas Barberousse, "Contracepción y feminidades: Un análisis de resistencias a la píldora”, Revista de Ciencias Sociales (Costa Rica) 143 (2014): 141-155.

22 Entrevista personal a “Adriana”, San José, Costa Rica, 21 de julio de 2014. 


\title{
Incidencia en otros espacios de la vida personal
}

Entre las ventajas que tiene el uso de contraceptivos se recalca el poder de decisión sobre sí mismas, de su cuerpo en función de los proyectos de vida que quieren, lo que les da seguridad, en lo que se percibe la apropiación del discurso feminista liberal de profesionalización, así como una decidida postura de empoderamiento ante las relaciones de pareja, en particular en lo que involucra la gestión de la maternidad. Por ejemplo, "Rosa" señaló cómo a veces los embarazos y los hijos fungen como cadenas en relaciones que, de otra manera, sería más sencillo abandonar, y evitarlos ayuda a mantener la libertad de decisión:

\begin{abstract}
"Lógicamente da la seguridad de que no va a depender uno de la otra persona para hacer su vida futura, sino que de alguna manera está uno liberado de una relación que por causa de un embarazo había que seguirla teniendo, o de una relación en la cual no se quiere la responsabilidad de criar un hijo, eso fue la más efectivo que hubo". ${ }^{23}$
\end{abstract}

"Fabiola", quien es una joven académica del rango de edad de 25 a 40 años, soltera y sin hijos, comenta, en relación con los otros espacios en los que incide la utilización de contraceptivos, la importancia que tiene para ella el posponer o planear la maternidad tomando como punto de partida su carrera profesional e independencia económica. Así mismo, identifica que el control lo tiene ella, pues es quien consume los anticonceptivos, pero eso no define posiciones de poder dentro de su relación, ya que ninguno de los dos desea hijos por el momento:

\begin{abstract}
"Yo siento que el hecho de poder controlar si quedo embarazada o no sí me da control sobre mi cuerpo, sobre el hecho de que puedo esperar de que esté lista mentalmente por lo menos, o económicamente, laboralmente, para tener un hijo [...] lo veo más como una responsabilidad. Nadie más va a decidir eso por mí. En algún momento, por ejemplo, con mi ex novio, en algún momento me cuestionó que yo no me las estaba tomando [las píldoras] ¡cómo se le ocurre que no me las voy a tomar! Definitivamente el control lo tengo yo, porque tengo otras metas que quiero alcanzar primero". ${ }^{24}$
\end{abstract}

Por otra parte, se percibió la noción de que los hombres pueden ser indiferentes a las consecuencias del sexo sin anticonceptivos, y que permanecen formas de violencia simbólica, que de cierta manera justifican la distribución desigual de la responsabilidad entre los sexos hacia la reproducción, cuyas bases se

23 Entrevista personal a Rosa.

24 Entrevista personal a "Fabiola", San José, Costa Rica, 12 de agosto de 2014. 
encuentran en la dominación patriarcal sobre la sexualidad femenina que, a pesar de ser reconocida, se naturaliza o normatiza de formas más o menos conscientes por parte del sujeto dominado. ${ }^{25}$ Veamos los ejemplos de las mujeres mencionadas anteriormente, quienes son de diferentes generaciones. "Rosa" comentaba: "otra cosa es que la mujer lo aceptara tan bien -a tomarse los anticonceptivos, o ponerse un dispositivo intrauterino- porque el hombre generalmente, diay, es mucho más descuidado, muchas veces". ${ }^{26}$ Ella recuerda algunas de las discusiones sobre anticonceptivos que se dieron en el país y afirma que había cierto grado de resistencia a nivel social, que ella expresa en el "descuido de los hombres", y en la buena aceptación por parte de varias amigas.

Algunas generaciones después, Fabiola expresa desde su vivencia que posee totalmente el control sobre su fecundidad, pues identifica cierto nivel de indiferencia por parte de sus parejas en la planificación, quienes se despreocupan de los gastos de la consulta y los medicamentos. Dan por sentado que es trabajo de ella:

"Lo que sí es que la consulta y las pastillas tienen un costo, verdad, entonces ahí siempre he pensado: Bueno, le digo a mi pareja que me ayude a pagarlas, porque al fin y al cabo ambos nos beneficiamos, o mitad y mitad. Siempre he tenido esa duda, pero en realidad nunca lo he hecho, siempre he terminado pagándolas yo". ${ }^{27}$

Lo que se observa es un proceso de continuidad en la mentalidad que rige la articulación de algunas relaciones de pareja, al menos en lo que a la prevención de los embarazos concierne, en donde la carga sobre la contracepción ha recaído notablemente en las mujeres, responsabilidad justificada en el "descuido" o indiferencia de los hombres. Entonces, en este tipo de circunstancias las conductas que asumen los miembros de la pareja se reproducen en los roles género aprendidos. La continuidad de estos roles trasciende las delimitaciones que puedan haber por diferencias económicas - habitus de clase-, educativas o generacionales, a pesar de las formas de pensamiento y acción transgresoras que las mujeres ejecutarían en otros ámbitos de sus vidas.

No obstante, el poder de decisión sobre cada una de las etapas involucradas en la anticoncepción -el médico, el método, los costos, los tiempos-, también puede ser interpretado como un espacio a través del cual las mujeres reafirman la autogestión y apropiación de sus cuerpos, pues algunas consideran que no es negociable, evitan la dependencia económica para la planificación e intromisiones en decisiones íntimas.

\footnotetext{
25 Pierre Bourdieu, La dominación masculina (Barcelona, España: Editorial Anagrama, 2000), 12.

26 Entrevista personal a Rosa.

27 Entrevista personal a Fabiola.
} 
Se deben considerar las variantes existentes en las experiencias de cada mujer, que como vimos en párrafos anteriores, han tenido matices en los cuales la negociación de este aspecto de la vida sexual se ha repartido de formas poco usuales, ya sea porque se cedió el control -Adriana- o por solidaridad con sus parejas ante situaciones extremas, como las complicaciones de salud -Camila-. Así, la anticoncepción también ha fungido como un espacio para fortalecer los canales de comunicación, pues en ambos casos las mujeres indicaron haber conversado con sus esposos para acordar las alternativas, así como una expresión social de los alcances de los discursos feministas en la vida cotidiana de las personas, que han luchado por la equidad de género, incluyendo las responsabilidades ante la reproducción.

Los deseos de lo que cada una ha querido para sus vidas indican, a la vez, cuándo consideran que se debe negociar con sus compañeros y cuándo no. "Rebeca" tenía claros sus objetivos desde la época en que hacía sus estudios universitarios, y mantuvo una sólida negativa a vivir la maternidad, a pesar de que su esposo sí quería hijos. Al ser consultada sobre la incidencia que podía tener el uso de anticonceptivos en su relación, comenta:

"Los anticonceptivos son intrusivos, pero es una intrusión inmediata en respuesta hacia algo que uno no quiere. Yo estaba segura de lo que quería hacer: no me voy a casar, no voy a tener hijos; cuando me di cuenta estaba casada muy jovencita, y con respecto a mi cuerpo y a la maternidad yo decía: No quiero nada de eso. Pero por el otro lado estaba el deseo de mi esposo. Creo que él hubiera sido muy feliz si yo no hubiera usado ningún anticonceptivo desde el principio. Pero al final, el anticonceptivo te determina eso y un montón de cosas". ${ }^{28}$

En la vida de "María", de 55 años, profesional y madre de tres hijas, la utilización de estas tecnologías se dirigía más bien, a tener más descendencia. Al contraer matrimonio, su esposo hizo explícito su deseo de tener un solo hijo, con lo que ella no estuvo de acuerdo. Después de su primera niña, decidió prescindir del criterio de su pareja, de forma que los tiempos de la planificación corrieron por su cuenta y del médico:

"Yo preguntarle a mi esposo: Voy a tomar pastillas, voy a ponerme una $\mathrm{T}$ ¡No! La decisión era mía y con mi ginecólogo, porque él me decía: Mamita, usted no puede tomar pastillas [...] entonces fue cuando tomamos la decisión-entre mi ginecólogo y yo- de ponerme una $\mathrm{T}$ y luego quitármela. De haber sido por mi esposo, solo hubiera tenido uno, pero a mí nunca me ha parecido eso de una sola hija, se crían muy solos". ${ }^{29}$

28 Entrevista personal a Rebeca.

29 Entrevista personal a María, San José, Costa Rica, 5 de septiembre de 2014. 
El rol del médico en la prescripción de los anticonceptivos ha sido central para las mujeres entrevistadas, ya que todas indicaron haber usado estas tecnologías solo con supervisión del doctor por temor a los efectos que puedan generar en sus organismos. Efectivamente, hay un reconocimiento a este grupo profesional como portador de saberes en el área de la ciencia y la salud, que puede normalizar relaciones de poder verticales -como estuvo presente en la historia de "Daniela" - y su intervención necesaria en la toma de decisiones relacionadas con la maternidad, particularmente en lo que a tratamientos contraceptivos se refiere. De alguna manera, este grupo es un aliado también. No se debe dejar de lado, entonces, que el personal médico ha ocupado un sitio trascendental en la gestión que hacen las mujeres de sus cuerpos, y en la que sus parejas no median, y pueden quedar al margen por libre determinación de ellas en pro de sus deseos y proyectos de vida.

Este fenómeno bien podría ser leído dentro del marco de los procesos socioculturales y económicos acontecidos desde mediados del siglo XX, con los que las mujeres ganaron un abanico más amplio de espacios de acción, y libertad de decisión en torno a sus cuerpos y proyecciones de vida -mayor acceso a la educación superior, y a más áreas del mercado laboral, por ejemplo-. El estímulo a la apropiación de sus destinos ha creado situaciones en las que el hombre poco a poco ha ido perdiendo influencia en la determinación de aspectos tales como la procreación y el tamaño de su familia. Turner señala que, no obstante, en este contexto el personal médico aún funge papeles de "vigilancia sobre la familia, a la cual los maridos no pueden más [sic] controlar y monopolizar". ${ }^{30}$

\section{Anticoncepción e Iglesia}

La iglesia católica, institucionalmente, ha mantenido una posición contraria a la utilización de métodos de planificación artificiales. A través de la prensa ha expuesto sus bases ideológicas para oponerse a ellos, y siempre ha tenido algo que decir cada vez que se presenta una disputa que involucre la contracepción y el control sobre el cuerpo de las mujeres, particularmente en lo que a sexualidad respecta.

Bryan Turner afirma que "mostrar que un discurso es prevalente, no es demostrar que éste es plenamente efectivo", ${ }^{31}$ por tanto, en este apartado se intentará identificar la permeabilidad de los dogmas del catolicismo o sus bases discursivas, dentro de las normas con las cuales han actuado las mujeres entrevistadas en lo que concierne a la prevención de los embarazos.

Es importante retomar el hecho de que en Costa Rica el capital simbólico, económico y cultural que poseen las instituciones eclesiásticas -incluyendo las denominaciones cristianas evangélicas- las colocan en una posición de ventaja

30 Bryan Turner, El cuerpo y la sociedad (México, D.F.: Fondo de Cultura Económico - FCE, 1984), 268-9. 31 Ibid, 40. 
en el campo político, al poseer porciones de poder significativas, que operan desde el ámbito de las creencias, para ser llevadas hacia la práctica cotidiana.

Sin embargo, se han reconocido varias distancias en relación con el mensaje de la Iglesia y el diario vivir de las mujeres consultadas. Entre ellas persisten resistencias que abiertamente cuestionan y transgreden los mandatos del Vaticano en materia de sexualidad. Esto se debe, en parte, a la conciencia de las mujeres y de sus parejas de que la competencia de la religión en este campo es limitada, pues priman las capacidades económicas, los planes de vida y los deseos personales. También, a que algunas no profesan ninguna religión en particular o son evangélicas, de forma que varios de los dogmas propios del catolicismo no aplican para ellas.

Haciendo un recorrido por las historias de las mujeres entrevistadas, el patrón se caracteriza por la indiferencia o transgresión de la norma de que el uso de métodos anticonceptivos es pecado. A partir del aumento en la realización de cirugías de esterilización, en las décadas de 1970 y 1980 -cuadro 1- se presentaron discusiones que buscaban regular este tipo de intervenciones. En ese momento, la atención estuvo puesta sobre el cuerpo de las mujeres; sin embargo, las jerarquías eclesiásticas hicieron extensa su desaprobación a las esterilizaciones en ambos sexos. De acuerdo con lo narrado por "Camila", fue su esposo quien se hizo la vasectomía, pero antes, habían hecho uso del preservativo. No obstante, su cercano vínculo con la iglesia católica, ella reconoce la necesidad que tuvieron de controlar el número de hijos:

\begin{abstract}
"A pesar de que siempre he estado muy cerca de la Iglesia, yo nunca había visto eso como que sea un problema. La pareja tiene derecho a tener los hijos que pueda mantener $[\ldots]$ como pareja tenés que cuidarte y disfrutar del sexo, pero no con la preocupación de que ¡Ay! si en este momento quedo embarazada ¿Qué hago? No, porque nada hace uno con un montón de chiquitos si no les va a dar lo que ellos necesitan". ${ }^{32}$
\end{abstract}

En la cita anterior, se identifican dos aspectos importantes. En primer lugar, la apropiación/construcción de la representación social ${ }^{33}$ de paternidad responsable al hacer referencia directa a la determinación de la cantidad de hijos en función de las posibilidades materiales de brindarles calidad de vida, fundamento

32 Entrevista personal a Camila.

33 Desde sus múltiples definiciones, se pueden comprender las representaciones sociales como el conocimiento socialmente elaborado y compartido, asumido popularmente como una realidad dada e inamovible. Este se origina desde las experiencias, la información, las estructuras mentales e ideologías que recibimos y reproducimos a través de la cultura, la educación y la comunicación. Son una abstracción simbólica de la realidad, cuyo valor e identificación permanecen contenidos en el lenguaje, la sociedad, el espacio y el momento histórico que les da sentido. 
del argumento eclesiástico en la encíclica Humanae Vitae ${ }^{34}$ y principio ideológico del programa de planificación impulsado por el Estado desde 1968. En segundo término, el derecho de la pareja a disfrutar del sexo, disfrute que viene de cumplir el deber de cuidarse de un embarazo, haciendo mención sin tabús ni prejuicios, al placer sexual. Desde la perspectiva de la iglesia católica, el sexo por placer es pecaminoso y hedonista, pero parece que esta interpretación no llegó a tener mayor injerencia en la relación de pareja de la entrevistada en cuestión.

En el libro De ama de casa a 'mulier economicus', Flórez-Estrada explora la mediación entre religión y sexualidad. Al igual que la presente investigación, la autora identifica en el discurso de las informantes, actitudes pragmáticas entre el dogma y la acción, persistentes también en el actuar de representantes de la Iglesia -padres, curas- quienes algunas veces son relativamente flexibles al perdonar en confesión la intervención de tecnologías contraceptivas, ya que en términos generales "la Iglesia Católica pone por delante, en la práctica, su aspiración gubernativa y su vocación de preservar la administración de la moral como su espacio de poder exclusivo". ${ }^{35}$ Así, parece que es mejor absolver, antes que perder feligreses. Al respecto, la declaración de "Daniela" es representativa de la posición que varias mujeres mantienen:

"Considero yo que a veces la Iglesia tiene sus cosas. Pero por otro lado hay que ver lo que es traer un hijo al mundo, y es una irresponsabilidad traerlo solo por traerlo. A mí por lo general, lo que la Iglesia diga... conste que ¡soy católica al 100\% y Dios sabe que sí! Pero en esa área sí que no me quedé yo con tatica Dios. Como te digo, hasta depende del sacerdote que te confiese, porque hay unos que son más amplios, hay otros que no te dan la absolución, es muy variado". ${ }^{36}$

En el conjunto de las mujeres que afirmaron tener algún vínculo religioso con la iglesia católica o con grupos evangélicos, expresaron que realmente no sentían haber incurrido en un error al utilizar métodos anticonceptivos. Como estrategias optaron por omitir el asunto en el confesionario o no comulgar, pero eso de ninguna manera les generó cuestionamientos en cuanto a su proceder como creyentes. Al contrario, sí fue recurrente que justificaran su utilización en el discurso de la maternidad/paternidad responsable, pero con algunas variables a la conceptualización que ha dado la Iglesia. Por ejemplo, entre el grupo de mujeres de 25 a 40 años -las tres sin hijos-, "Ana", la más joven de las participantes, casada, sin hijos, supervisora y estudiante universitaria, afirmaba: "no me gustaría traer al mundo un hijo no

34 Paulo VI, Carta Encíclica Humanae Vitae (Vaticano: 25 de julio de 1968): Enunciado 10: La paternidad responsable. Disponible en: http://w2.vatican.va/content/paul-vi/es/encyclicals/documents/hf_p-vi_ enc 25071968 humanae-vitae.html

35 Flórez-Estrada, 52.

36 Entrevista personal a Daniela. 
planeado", ${ }^{37}$ planteamiento recurrente en ese segmento etáreo independientemente de su grado educativo, pues sus prioridades estaban en su carrera, el trabajo, la relación de pareja, la recreación o en establecerse económicamente.

\section{Conclusiones}

Lo que nos puedan decir la evidencia material -prensa, estadísticas o libros- sobre el uso que se ha hecho de método anticonceptivos es apenas un esbozo de lo que realmente ocurre en la vida de las mujeres, y la manera y los propósitos por los que ellas se deciden a la planificación contraceptiva. Una parte significativa de las mujeres de las zonas urbanas de Costa Rica ha hecho uso de estas tecnologías, independientemente de sus objetivos y perspectivas de vida: algunas quisieron evitar la maternidad de manera tajante; otras, la buscaron anheladamente; mientras hubo a quienes les llegó sin avisar, obligándolas a tomar medidas preventivas. Tienen en común que hicieron intervenir en sus cuerpos sustancias o medios que las ayudarían a materializar ciertas metas.

Así, la utilización de los métodos contraceptivos se ha llegado a articular como un elemento perteneciente al conjunto de estrategias de las que se valen las mujeres, no solo para controlar la fecundidad, sino también para articular sus subjetividades, plasmadas en sus percepciones de la reproducción, las relaciones de género y los roles sociales, y que se imbrican con la interiorización de discursos e ideologías feministas que promulgan la autonomía de las mujeres, las cuales son una constante también en las historias de las colaboradoras, quienes se reconocen sujetos de derechos y dueñas de sus cuerpos, al menos en lo que anticoncepción respecta.

Sin embargo, a la par de los avances en las formas de apropiación de la sexualidad y gestión de las capacidades reproductivas, corren paralelas representaciones sociales que efectivamente operan dentro de los imaginarios colectivos. Un ejemplo de esto se evidencia en las connotaciones desde las cuales ha sido asumida la cirugía de vasectomía, como una amenaza a la virilidad. El dicho "quedar como un buey", y los bajos índices de esterilizaciones en hombres -a pesar del incremento que han presentado desde la década de los noventa- expresa, a decir de Pierre Bourdieu, "el aspecto ético de la virilidad, en cuanto esencia del vir, virtus, principio de la conservación y del aumento del honor [...] a través especialmente de las demostraciones de la fuerza sexual", ${ }^{38}$ constitutiva de la masculinidad en las sociedades patriarcales y que encierra tras de sí una continuidad en el habitus de género: ${ }^{39}$ el asumir que la responsabilidad de la reproducción es

37 Entrevista personal a Ana, San José, Costa Rica, 3 de octubre de 2014.

38 Bourdieu, La dominación masculina, 24.

39 El concepto de habitusde género, es propiamente desarrollado a partir de Bourdieu, por la socióloga María Flórez-Estrada Pimentel en el libro: Economía del género. El valor simbólico y económico de las mujeres (Costa Rica: EUCR, 2010), xii-xiii, así como en el análisis que presenta la investigación. 
un asunto de mujeres, práctica presente en las narraciones de las entrevistadas, perpetúa los desplazamientos y repliegues del poder, en la lucha por el control de los cuerpos femeninos.

A pesar de los puntos convergentes en el tema, dos asuntos no se pueden negar: los anticonceptivos se han convertido en herramientas que han posibilitado la ampliación de los campos de acción de las mujeres y que su presencia en el espacio público se prolongue; así como ha facilitado la materialización de sus decisiones sobre las capacidades reproductivas, en función de sus proyectos. Han formado parte de sus vidas y contribuyen a construir sus subjetividades y vivencias con vistas a la independencia y autodeterminación. A la vez, denotan nuevas formas de disciplinas corporales, al incurrir en rituales y rutinas que procuran el dominio sobre los ciclos de fecundidad, así como nuevos guiones performativos del género, en donde las tecnologías contraceptivas, de cierta manera, han contribuido a legitimar los roles sexuales impuestos por el patriarcado.

Las formas que han tomado las disputas por el control sobre el cuerpo de la mujer, particularmente en lo que concierne a las capacidades reproductivas, evidencia que a pesar de los márgenes que brindan los métodos de anticoncepción en la autonomía de las usuarias -lo que quedó claro en las potencialidades que le han dado las entrevistadas-, estas libertades permanecen condicionadas por los discursos y las prácticas del sistema patriarcal, que expresan sus continuidades en formas de violencia simbólica, sutilmente reproducidas en la distribución desigual de las responsabilidades para evitar los embarazos, lo cual denota las construcciones sociales sobre los roles de género. 